Int. J. Electrochem. Sci., 11 (2016) $6705-6718$

International Journal of

ELECTROCHEMICAL

SCIENCE

www.electrochemsci.org

\title{
Optimization of Landfill Leachate Treatment Process by Electrocoagulation, Electroflotation and Sedimentation Sequential Method
}

Ghasem Hassani ${ }^{1}$, Abdolazim Alinejad ${ }^{2}$, Abdolmohammad Sadat ${ }^{3 *}$, Abdolreza Esmaeili ${ }^{4}$, Morteza Ziaei ${ }^{5}$, Ali Akbar Bazrafshan ${ }^{6}$, Tayebe Sadat ${ }^{7}$

${ }^{1}$ Department of Environmental Health Engineering, Faculty of Health, Ahvaz Jundishapur University of Medical Sciences, Ahvaz, Iran

${ }^{2}$ Department of Environmental Health Engineering, School of Health, Shahid Beheshti University of

Medical Sciences, Tehran, Iran

${ }^{3}$ Social Determinants of Health Research Center, Yasuj University of Medical Sciences, Yasuj, Iran

${ }^{4}$ Izeh Health Network, Deputy of Health, Ahvaz Jundishapur University of Medical Sciences, Ahvaz, Iran

${ }^{5}$ BSc in Environmental Health Engineering, Kashan, Iran

${ }^{6}$ Chemistry Department, Yasouj University, Yasouj 75918-74831, Iran

${ }^{7}$ M.A of English language Teaching, Department of Education, Boyer Ahmad Education

Organization, Yasouj, Iran

*Email: Abdolmohammadsadat@yahoo.com

doi: $10.20964 / 2016.08 .10$

Received: 21 February 2016/Accepted: 3 May 2016 / Published: 7 July 2016

This work is dealing with the performance of a sequential Electrocoagulation (EC), Electroflotation (EF), and sedimentation method for the treatment of landfill leachate of Gachsaran city. Effective parameters on the EC process such as electrode type, electrode distance, voltage, process time, and effect of $\mathrm{pH}$ have been investigated. Various water treatment criteria such as Chemical Oxygen Demand (COD), Total Suspended Solid (TSS), Oil and Grease (O\&G) and turbidity were used to assess process efficiency. Also removal of Total Kjehldahl Nitrogen (TKN) and phosphorus was surveyed as nutrient pollutant criteria. Finally removal of $\mathrm{Pb}$ and $\mathrm{Cr}$ as typical heavy metals was assessed. Generally, using iron electrode as anode at the optimum condition of $\mathrm{pH}=8$, Voltage $=40 \mathrm{~V}$, Electrode Distance $=2 \mathrm{~cm}$, and contact time of $90 \mathrm{~min}$, the removal efficiency of COD, TSS, O\&G, Turbidity, TKN, total phosphorus, $\mathrm{Cr}$, and $\mathrm{Pb}$ were obtained $86.9 \%, 88.7 \%, 90.2,93.7 \%, 81.8 \%$, $90.3 \%, 70 \%$, and $66 \%$ respectively. The results show that this technique is a promising method for treatment of the landfill leachate. 
Keywords: landfill leachate treatment; Electrocoagulation; Electroflotation; Sedimentation; nutrient removal; heavy metals removal.

\section{$\underline{\text { FULLTEXT }}$}

(C) 2016 The Authors. Published by ESG (www.electrochemsci.org). This article is an open access article distributed under the terms and conditions of the Creative Commons Attribution license (http://creativecommons.org/licenses/by/4.0/). 